INTERNATIONAL DESIGN CONFERENCE - DESIGN 2018

https://doi.org/10.21278/idc.2018.0255

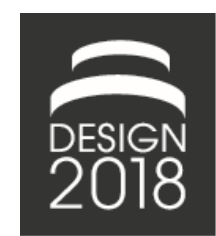

\title{
THE CHARACTERISTICS OF SUCCESSFUL MEANING CONSTRUCTION IN DESIGN TEAMS
}

\author{
L. S. Knudsen, C. Tollestrup and L. M. Haase
}

\begin{abstract}
Creation of new meanings of products and services is acknowledged as the key skill of designers today. Still, it is also recognised as a difficult competence to acquire and moreover, there is very little guidance for novice designers or non-designers on how to practice this creation of new products meanings. In this study, we explore the meaning construction process in four novice design teams. The study reveals a remarkable difference between high-grade and low-grade students related both to their approach to a design problem as well as their prioritisation of aspects in the design process.
\end{abstract}

Keywords: meaning making, early design phase, design teams, new product development

\section{Introduction}

In recent years, practitioners and scholars have shown growing interest in design as a strategic tool and as a driver for innovation (Verganti, 2003). Design as a strategy to innovation focuses on the creation of truly meaningful products and services where the new meanings are the key to strategic market positioning and commercial success (Verganti, 2003; Dell'Era and Verganti, 2010). In the designdriven innovation perspective, design becomes a situated activity of meaning creation (Harrison et al., 2007; Ylirisku et al., 2009) and accordingly, the key skill of designers becomes the ability to master this creation of product meaning. In spite of an increasing interest in the field of design-driven innovation, the creation of product meaning is rarely addressed. And when it is addressed, it is often from a macro level perspective, in which the micro-level insights of meaning construction activities are missing.

In innovation management literature, product meaning is commonly recognised as a rather complex phenomenon that is difficult to manage. The complexity in product meaning stems from the fact that meaning is context dependent and socially constructed. Thus, what people perceive as being meaningful is dependent on their context and based on previous experiences as well as social and cultural factors. Moreover, research from innovation management discusses the design-driven innovation approach on a macro-level, addressing management activities and strategies in the design process (see e.g. Dell'Era and Verganti, 2009, 2010; Öberg, 2015).

Likewise, in the field of design there is fairly little research on the creation of product meaning. In design research, product meaning or meaning making is more often discussed in terms of what products communicate and how users perceive and experience existing products (e.g. Kazmierczak, 2003; Krippendorff, 2006; Desmet and Hekkert, 2007; Crilly, 2011; Rampino, 2011; Goto and Ishida, 2014). Most research on meaning making builds on the understanding that products are what they communicate they are and thus, a product's meaning is only present in relation to people, i.e. when it is received by someone. Krippendorff argues that designers' understanding of how users make sense of the product is a prerequisite for meaning creation (Krippendorff, 2006). But one thing is how people make sense of a 
product, another thing is what the designers intended to communicate with that product. Product meaning in design research is rarely addressed in terms of how it is created on an operational level in the design process. That is in spite of that more studies point to a gap in design's contribution to innovation (e.g. Rindova and Petkova, 2007; Jahnke, 2013).

The aim of this study is to explore the process of meaning construction in the context of master design students and identify some of the approaches that support novice design teams in creating new product meaning. Through real-time tracking and follow-up interviews, we compare how high-grade and lowgrade novice design teams approach and manage the challenge of creating new product meaning. The research question of this study is therefore: what characterises a successful meaning creation process in novice design teams? And what are the operational activities in this process? But firstly, we seek to establish the theoretical foundation for the study in order to explore the phenomenon of meaning creation.

\section{Towards a model exploring the characteristics of meaning creation}

Until now, there has been no clear description of meaning construction as a design practice on an operational level. However, many researchers argue that creation of meanings starts from a vision (Hill and Levenhagen, 1995; Verganti, 2009; Magnusson and Nilsson, 2011; Sarpong and MacLean, 2012; Verganti and Öberg, 2013). Furthermore, creating new product meanings is based on new and emerging changes in the social cultural models and new types of behaviours. Hence, in this paper we suggest the use of vision models and tools from design as a starting point for understanding the process of meaning creation. The first model we identify as relevant is Vision in Product design (ViP model) by Hekkert and van Dijk (2011) and the second is the Vision-based model by Lerdahl (2001).

The ViP model (Figure 1) is seen as relevant to meaning creation as it explores the characteristics of visioning from a process perspective.

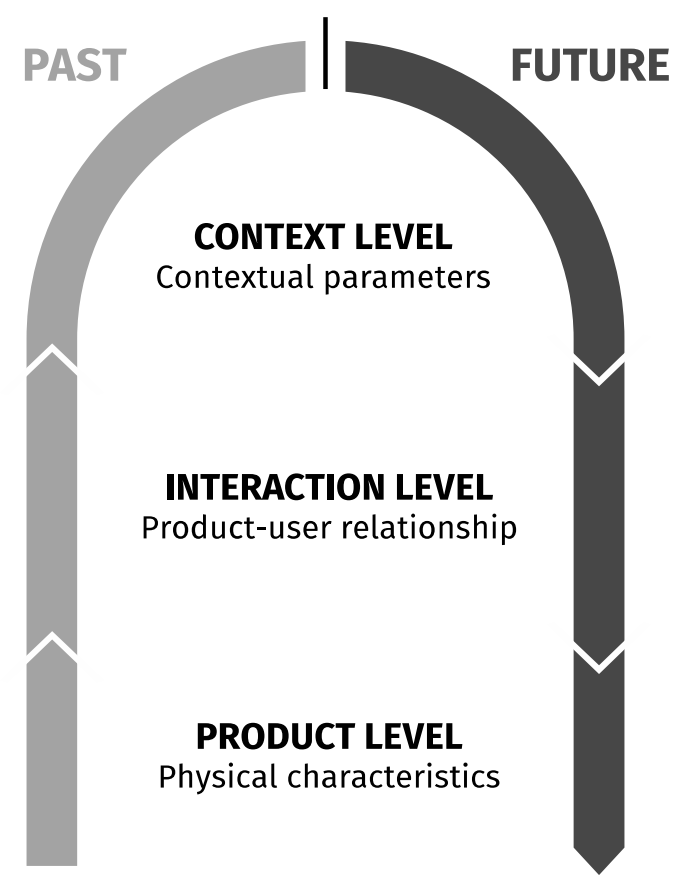

Figure 1. Vision in Product design (ViP) model (based on Hekkert and van Dijk, 2011, p. 119)

The model describes the process of how visions are developed based on past experiences of products. Through the model, Hekkert and van Dijk (2011) argue that a vision starts from an understanding of an existing product based on the product experience or interactions it provides in a particular context (they 
call this process the 'deconstruction phase'). This understanding of the past situation becomes the starting point for envisioning a new meaning of a future product in a new context, which is communicated to the user through the product's physical characteristics. Based on the ViP model, we argue that the creation of new product meanings can be explored as a process of deconstructing the meaning of existing products in existing contexts and then using this as a stepping stone to generate new product meanings, firstly by envisioning how the future context of the product might be and then by creating product meaning in respect to the interaction level and the product level.

To supplement the process perspective from the ViP model, we have also found the Value-vision-based model (Lerdahl, 2001) relevant in respect to meaning creation. Rather than addressing the process perspective as the ViP approach, the Value-vision-based model defines different aspects of the vision. This approach is seen as useful to describe how related aspects of the product influences the creation of the product meaning. The model describes four levels of abstraction: the spiritual level, the contextual level, the principal level and the material level (see Figure 2).
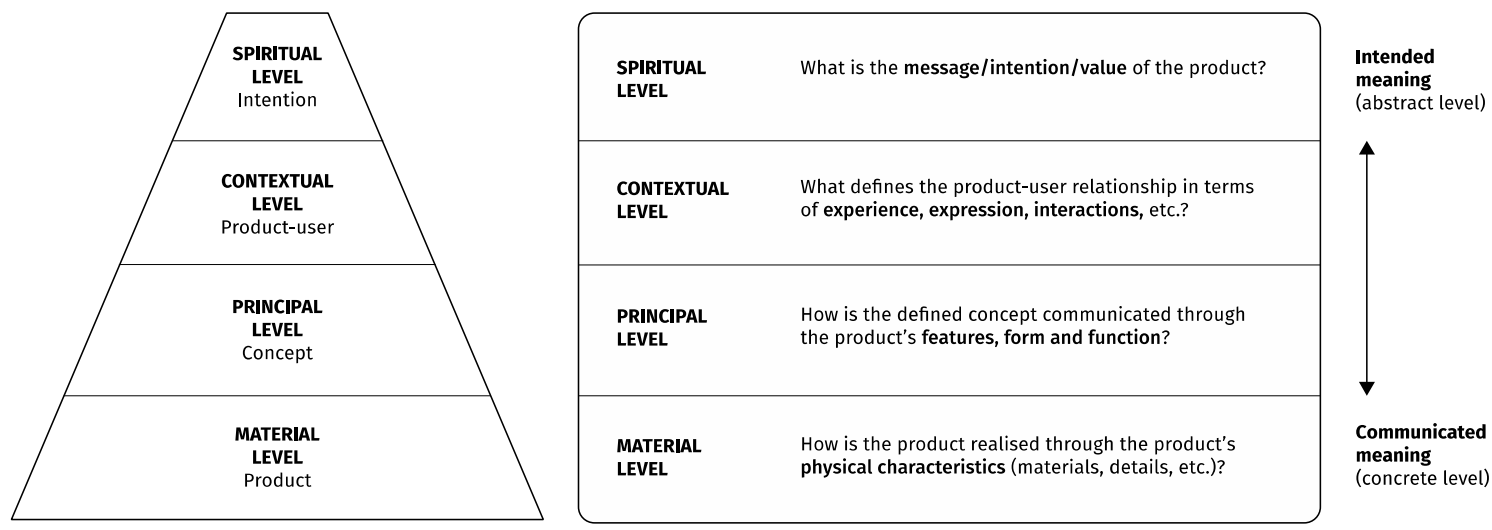

Figure 2. Vision-based model (based on Lerdahl, 2001, p. 101)

The top level is the spiritual level, which refers to the intention of the future product. At this level, the product is defined in terms of the immaterial values it should provide to the users and to society, i.e. its overall message. The second level is the contextual level, which refers to the intended experience and expression of the future product. At this level, the product is defined in terms of how the user should perceive the product, that is the social setting the product is intended for. In this perspective, it defines the intended product-user relationship (the interaction or the story of the product). The third level of the model is the principal level, which refers to the conceptual aspects of the product, e.g. the functions and features it provides. The bottom level is the material level, which refers to the tangible product specifications or physical characteristics of the product, e.g. product details, materials, and construction elements. While the first two levels refer to the immaterial aspects of the product, the other two relates to the tangible aspects of the product. The product meaning can be understood in terms of the coherence between these levels, that is how the intention (immaterial aspect) is communicated through the product's physical characteristics (tangible level). With the Vision-based model we argue that meaning creation can be explored in relation to different aspects of the product, e.g. in relation to experience, expression, interactions, feature, form and function etc.

By combining the insights from the ViP model and the Vision-based model, we arrive at an explorative model for understanding meaning creation (see Figure 3). Based on the two models, we suggest that new product meanings can be explored as a process of deconstructing the meaning of existing products in existing contexts and then using this as a stepping stone to generate new product meanings, firstly by envisioning the future context of the product and then by creating product meaning in respect to experience, expression, interactions, features, form and function of the product. 


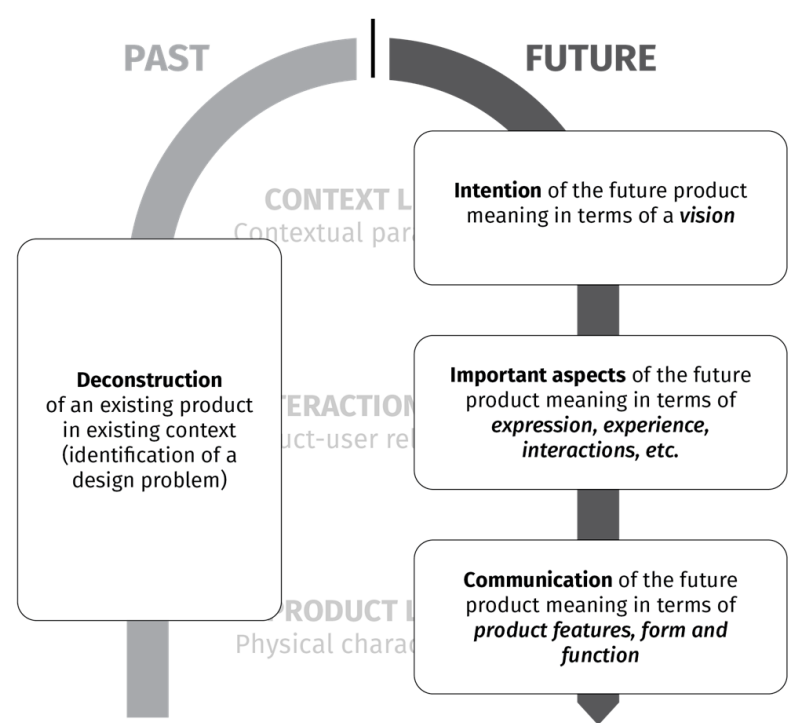

Figure 3. An explorative model for understanding meaning creation (ViP model and Vision-based model combined)

\section{Research design and methods}

The data is generated from two facilitated workshops and a follow-up interview with four student teams (4-5 members) in their first year of the master programme at Industrial Design at Aalborg University. The theme of their projects is given by the company B8, which is a major Danish manufacturer of office furniture and provider of interior design solutions. The teams are assigned to develop a proposal for new innovative solutions involving a product related to relevant technologies, markets and users, and business strategies. There is no given definition of the problem and therefore, it is fully up to each team how they will define, see and approach the design situation.

The workshops are facilitated at two different stages in the students' project: the first one at a very early stage and the second one at a later point. Each workshop is a video-recorded 3-hour long session with one team at a time. The aim of the workshops is to collect real-time data from the meaning construction process, that is in the moment when they are to discuss and determine relevant aspects of the future product at the given project stage. For that we use the combined model of ViP and the Vision-based methodology (Figure 3): firstly, the teams are asked how they see and understand the past situation in terms of the problem(s) identified (deconstruction of existing situation). Secondly, the main vision for the product is questioned in terms of the aspired vision for the future context. Then they are asked to identify the most important aspects to address in the future product and finally, concrete solution principles are questioned in order to capture how they would achieve the vision and related aspects. The questions are organised in a template version which serves as a basis for discussions in the teams.

During the workshops, the different levels of the product meaning become apparent as well as the different aspects of the product. At the end of each workshop, the teams are asked to identify and prioritise the three most important aspects to their future product. This gives an instant picture of their intentions, related aspects and possible solution principles. Hence, data from the workshops provides insight into the teams' internal reflections about how they collectively see and understand their project and how they aspire to approach and deal with it. The facilitation of the workshop is mainly instructionbased, meaning that the facilitator is only giving an instruction prior to the different steps, i.e. no guidance is provided in the process. Consequently, how participants approach the templates, how the team prioritises relevant aspects or selects topics for discussions etc. is fully controlled by the team itself. The aim of this setup is to keep an explorative nature of the study and thus affect the content as little as possible.

After the examination, the process is followed up by a group interview (audio-recorded) with each team based on their final proposal. The aim of the interviews is to capture their post reflections and underlying 
reasoning behind product details. Most importantly, however, is to identify how they define the intended and communicated product meaning in a retrospective view.

The data is analysed with attention to the underlying process, levels of abstraction and relevant aspects prioritised in each team. The analysis is conducted after the grading where the teams are categorised into high-grade and low-grade teams. The categorisation is based on the teams' final grades at their oral examination at the end of the project where the evaluation is based on both their process and their final proposal documented in a report. The overall aim is to identify whether there is any connection between meaning construction activities and a successful/unsuccessful outcome.

\subsection{Introduction to the cases}

The design brief given from the company B8 is fairly open: 'to design the new B8 element' in different environments specified for each team: for conferences, for hospitals, for office spaces, and for start-ups. Each case is briefly introduced in the following and the final proposals are illustrated in Figure 4.
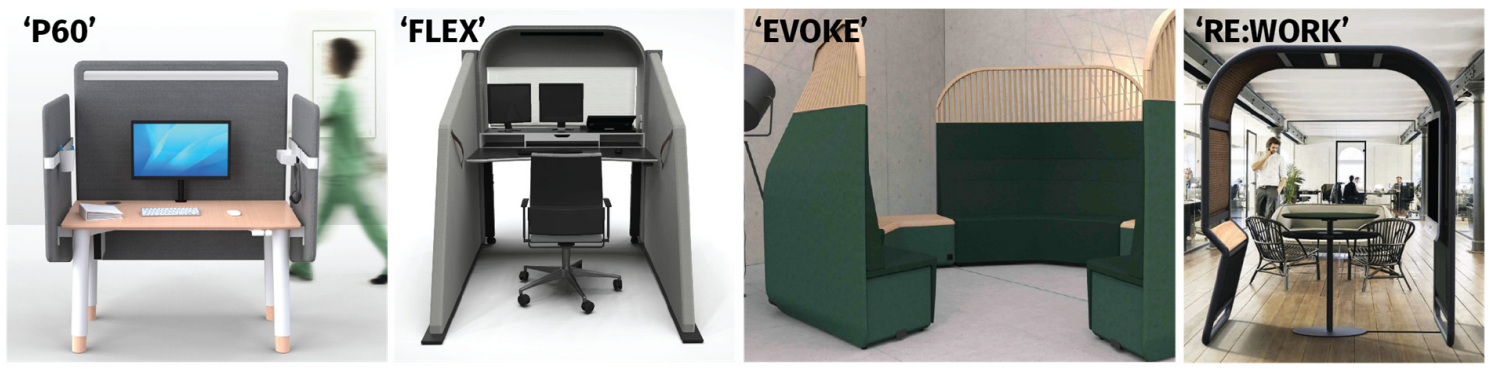

Figure 4. Final proposals of the student projects

\subsection{1. 'P60' - a pod workspace for hospitals}

'P60' is a pod workspace for nurses and doctors at hospitals. It is intended for focused work in a hectic daily environment where documentation and other related desk work is a big part of the daily routines besides the care of patients. The identified problem in the team is related to noise levels and visual distractions and accordingly low concentration and decreased efficient work. The final proposal is a working desk with acoustic walls and focused light intended to enhance concentration and eliminate distractions from the hectic environment at hospitals. Height and direction of light is adjustable for the individual employee.

\subsection{2. 'Flex'-a pod for the office environment}

'Flex' is a pod workspace targeted towards the open office environments. The identified problem stems from the concept of Activity Based Workspaces which have become increasingly popular at open office environments. However, many employees feel a lack of individual control as well as the possibility to concentrate on their individual work. Therefore, 'Flex' is intended for employees who both want to exclude from the office environment to achieve more concentrated and efficient work and still feel the physical sense of belonging at the office. The adjustable side screens enable the employee to shift between two modes of working: focused work and collaborative work and thus it accommodates with the idea of having flexible workspaces.

\subsection{3. 'Evoke'- a furniture for a lounge area at conferences}

'Evoke' is a furniture system for lounge areas at conferences. The intention with the product is to facilitate the informal conversation between professionals at conferences by creating a more relaxed atmosphere in the lounge areas. The solution is an angled couch with additional elements that together can create a variety of small spaces in open environments. The idea is to create partly enclosed areas that promotes an informal atmosphere and thus strengthen the social experience and the networking environment at different types of conferences. 


\subsection{4. 'Re:work' - a room-in-room solution for start-up communities}

'Re:work' is a room-in-room solution for the professional workspace in start-up communities. It is intended for efficient and short stand-up meetings in an open office environment where it acts as a gathering point in-between primary workspaces. The semi-closed structure with sound absorbing walls enables the undisturbed and focused conversation, and its light expression makes it fit a broad range of different environments in start-up communities.

\section{Results and discussion of findings}

Based on the analysis of data from workshops and interviews, the study indicates a significant difference between the high-grade teams and low-grade teams which refers both to their underlying process and their final proposals. These findings will be elaborated in this section.

The assessment and grades from the teams' oral examination divide the teams into two categories: the projects 'Evoke' and 'Re:work' are categorised as the high-grade or successful teams and likewise, 'Flex' and 'P60' are categorised as low-grade or un-successful teams.

\subsection{Successful meaning construction seeks underlying reasons of user behaviour}

In all four cases, the teams identify a key problem in a past context but their approach to the problem differs remarkably. The low-grade teams move rapidly from identification of an outlined problem into the solution space by proposing possible concrete solutions. More specifically, they focus on resolving or improving the existing situation. In contrast, the high-grade teams approach the problem by exploring the underlying reason for what has caused the problem. They seek the underlying reasons for identified user needs or behaviour. Their different approaches are illustrated in Figure 5 which is further elaborated with examples in the following.

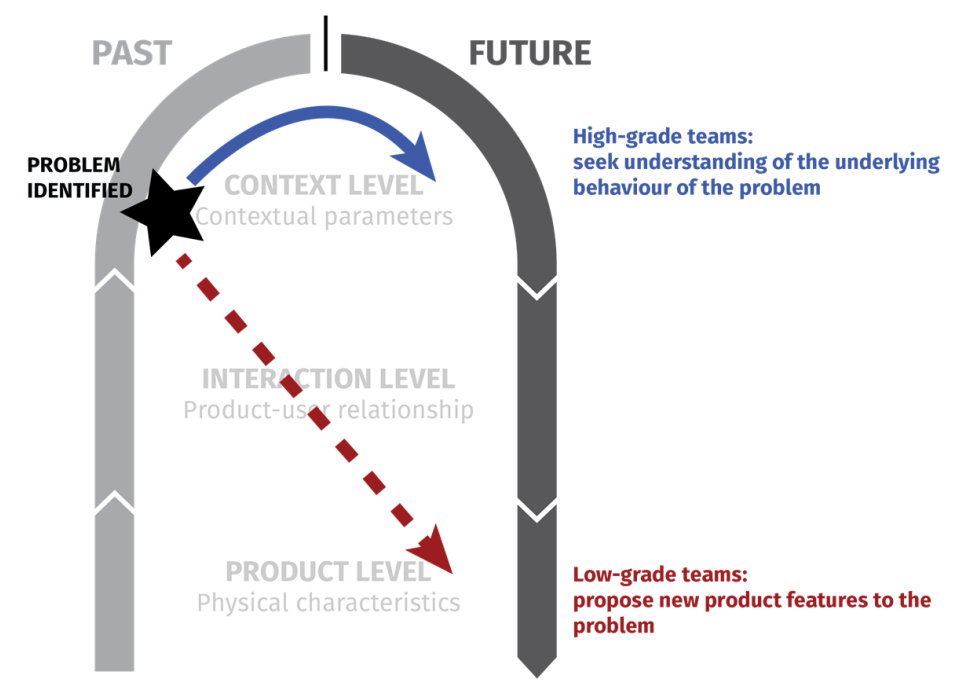

Figure 5. Differences between high-grade and low-grade teams in their approach to problem identified

An example of the low-grade teams' approach is the hospital case ('P60'), where the team identifies bad working conditions for nurses and doctors related to noise and light in a hectic environment. With an increased number of daily tasks for nurses and doctors, the team points to a need to integrate retreat zones for focused work with less disturbance from the surroundings, but still be available in case of sudden patient calls. Their discussion at the workshops reflects very general visions for the project like 'easy to use' and 'efficient work' which are not unique to the context of hospitals and as a result, they do not provide any direction to the project. The team approaches the situation by exploring possible product features to overcome the noise and improve light conditions, which becomes the driving aspects in the design process. The same approach is present in the office case ('Flex'), where the team identifies 
a paradoxical situation where employees on the one hand have a need for a personal space but on the other hand there are different working tasks that require different working spaces. E.g. there are both working tasks that require a focus zone and other tasks that require a collaboration environment. Based on this situation, the team starts exploring how a working desk can be transformable between the two working modes: focus and collaboration. More specifically, they explore possible product features to the problem. Also in this case, their visions are generally oriented, e.g. 'provide different working needs' or 'acoustic walls and focused light'. In other words, they are oriented towards the product level focusing on how the future working space can include and exclude surroundings in the office space.

In the high-grade teams, the approach to the identified problem is remarkably different. For instance, in the start-up case ('Re:work'), the team recognises that many start-up communities have a shared space, often furnished as a lounge for relaxed work or breaks. Lounge areas are commonly used in office spaces but this is not the case in start-up environments. The team approaches this situation by exploring the core of the problem by critically asking: why are the spaces not used? They are questioning the user behaviour and identify several issues from the employees' point of view: the shared spaces are regarded as an in-between space with a lot of 'traffic' and accordingly, they perceive the environment as 'being in the middle' which is not efficient in their daily work. The start-up culture is spirited and dynamic and therefore, it does not fit into the relaxed environment. 'You do not work in a couch' is a statement that the team works around. Therefore, instead of tapping into the existing working culture of the relaxed environment the team aspires to create a new working culture - a space for efficient, short meetings for small teams. In the conference case ('Evoke'), the team identifies that human interaction between professionals is the main reason for why people attend conferences. They even point to the importance of the social context of experience (and only partially the content of conferences that is available elsewhere) that is what makes a conference worth its effort. This situation points to a paradox where on the one hand, the networking environment is the most important aspect of conferences. On the other hand, the existing environment promotes a very formal and stringent interaction and is thus perceived as an impersonal experience. The team's approach to this situation is characterised by being investigative in their understanding the underlying behaviour at conferences. They start exploring balance of a professional conversation in an informal environment, e.g. related to body language, the intimate space, interaction behaviour, etc. Also in this case, the team focuses on aspiring a new vision: to change the formal culture of conferences into an informal experience between professionals.

By comparing the data from the workshops, we can initially conclude that the problem identified in all cases is approached quite differently in the low- and high-grade teams, respectively. While the highgrade teams explore the reason behind the underlying behaviour of the problem, the low-grade teams explore possible product features to resolve the problem immediately. More specifically, the high-grade teams' ability to formulate a clear direction or vision for the future context (based on their deep understanding of the past situation) seems to be the entry point for creating a new product meaning. In the low-grade teams, the underlying reason to the problem does not become clear and deeper insights about user needs or behaviour are not identified. Instead, they seem to focus on the symptoms of the problem and as a result, they formulate more general visions which are concretely oriented towards product specifications and features. This finding indicates that the approach to an identified problem plays a significant role in the early phases of the meaning construction process. It requires a deep understanding of the problem at hand in order to formulate a clear vision that provides a direction for creating a new product meaning. What is further remarkable when comparing the cases, is not only the approach to the problem - also the ability to add more levels and aspects to the future product meaning seems to be a crucial factor.

\subsection{Successful teams add more levels to the new product meaning}

Based on the high-grade teams' approach to the identified problem, they envisioned not only a new product context but they also managed different aspects of the product such as experience, expression, interactions, market, etc. which refer to the abstract level of the vision-based model (Figure 2). This is in contrast to the low-grade teams who stay on the principal level focusing on improving the existing situation by proposing new product features (differences are illustrated in Figure 6). 


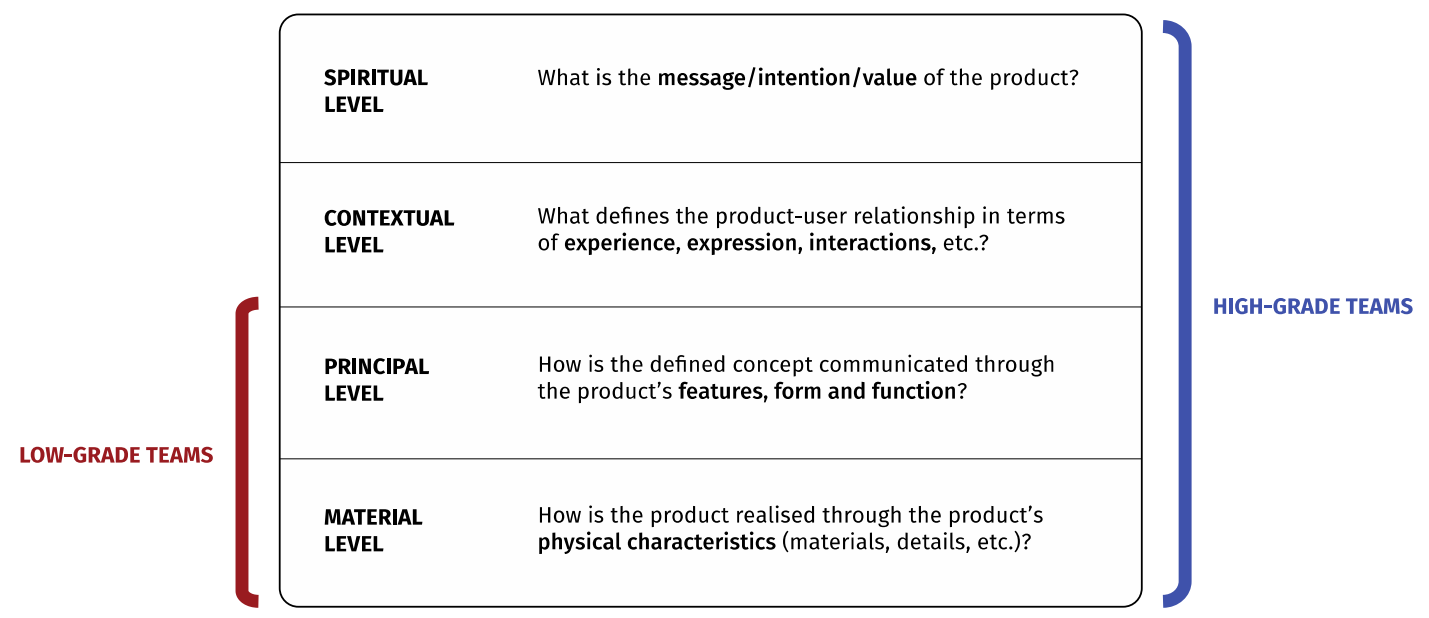

Figure 6. Differences between high-grade and low-grade teams in their level of abstraction

In the high-grade teams, they start building up the future product meaning from the overall intention with the future product (abstract level). For instance, the intention of 'Evoke' is to facilitate the informal conversation at conferences and thus change the behaviour of professionals in this environment. In the same way 'Re:work' refers to a change of behaviour in the context of start-ups: from a relaxed environment to an efficient working space. With their product, they envision to create new type of working space for efficient and undisturbed stand-up meetings, pitches and collaborative work. In the low-grade teams, it becomes a challenge to identify a clear message/intention with the product. The lowgrade teams identify different aspects to the problem at hand but the intention of them (why they are important) are only vaguely defined. They are oriented towards the physical level and therefore, it seems hard to relate to the immaterial values of the future product.

In order to support the main intention/message with the product, the high-grade teams add different aspects that concern experience, interactions, expression, business, etc. (the contextual level in the vision-based model). For instance, in the start-up case 'Re:work', the expression of the product should balance the generic and iconic: it should both be recognisable but it should also fit into many different kinds of environments. Regarding the user experience of the product, it should provide the feeling 'equality' between employees at the meeting: the sitting position around a meeting table with a presenter at the end is regarded as a hierarchy in the interaction between people. Therefore, 'Re:work' facilitates a standing position to create the equal feeling - only an angled seat for resting (like on a metro station) is provided as an integrated part of the iconic shape. Likewise, 'transparency' is also a leading keyword in the design process. It relates firstly to the experience of the open shape that allows unobstructed passing of daylight, sight and movement and secondly, it relates to the transparent structure of the construction where connection points are easily decoded so that companies can install it themselves. Furthermore, 'transparency' also relates to the visible availability of the meeting room - you do not disturb the meeting to check if it is available or not. In this sense, the aspects are linked together in a meaningful way: leading parameters are consistently used throughout all aspects and serve as reference points in decisions about the product.

In contrast to the high-grade teams, the identified aspects in the low-grade teams are hardly described in terms of the intended values it should provide for the user. Therefore, it becomes hard to follow the underlying reasoning behind the intended product meaning because they are mainly considered on a product level, e.g. whether the proposed feature reduced the noise or not. This finding may be a symptom of the teams' approach to the main problem identified: because the high-grade teams reach a deep understanding of the underlying behaviour or need, they are able to formulate a clear intention/message with the product.

\subsection{Successful teams identify and prioritise different aspects of the future product meaning}

The final remarkable difference between the high-grade and low-grade teams is their ability to prioritise a key aspect in their design process. All teams identify different aspects to the intended product but their 
handling of the aspects differs. High-grade teams prioritise one key aspect as the most important to address in the product and accordingly, this aspect becomes the driver of the meaning construction process. This is in contrast to the low-grade teams which regard more aspects as equally important (Figure 7). Moreover, the low-grade teams are challenged to communicate their aspired meaning through the tangible level of the product. In that perspective, the levels in the Vision-based model are not clearly linked together which becomes a crucial factor of successful meaning construction.
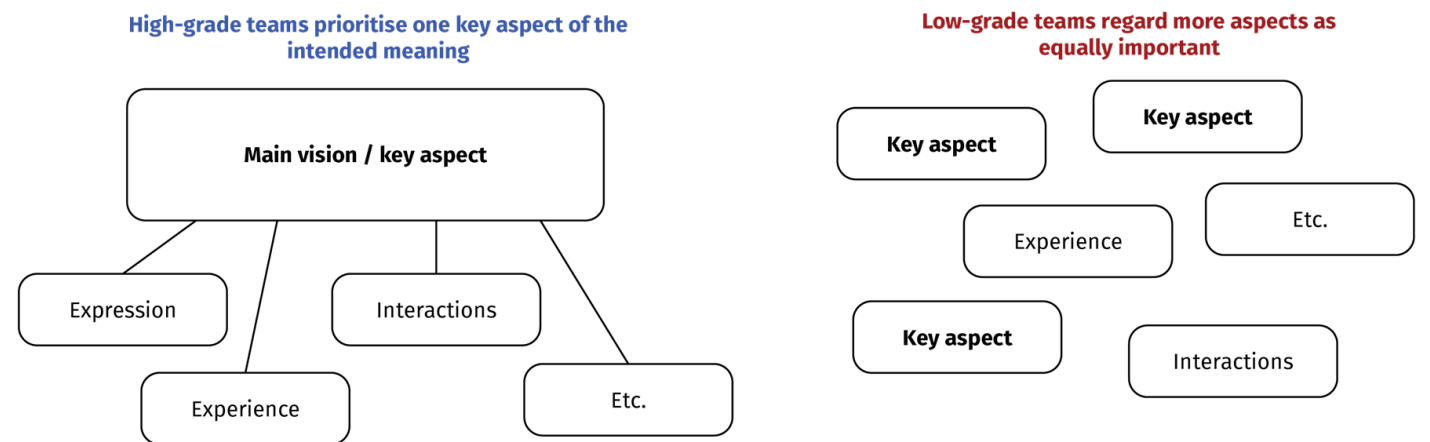

Figure 7. Differences between high-grade and low-grade teams in their prioritising of aspects

For instance, in the hospital case ('P60'), the team prioritises reduction of noise and visual distractions, and collaborative work as equally important aspects to achieve. This structure becomes apparent in the final proposal where it express a jumble form with no remarkable visual expression or a unique 'selling point' that stands out from already existing solutions on the market. Furthermore, it becomes hard to decode the intended meaning of the product. E.g. 'P60' is intended for short working tasks and for two employees working together on the same task. This point is hardly communicated in the final proposal where it may rather be perceived as a product for immersion and for one single person. In this sense, the link between the different levels in the Vision-based model is a significant challenge for the low-grade teams to achieve. The same pattern is present in 'Flex' (the pod for office spaces). Even in a retrospective view, the team points to equally important aspects of the product: it is both the feature that it can be stacked so it is easily stored, transported and installed but also the shielding feature which provides the user to include and exclude from the office environment. As a result, the final proposal express a mixture of forms (rather than an integrated form) and again the overall intention or message of the product becomes hard to decode.

In the high-grade teams on the other hand, they focus on one key user aspect to achieve and accordingly identify relevant aspects to it in order to support that experience. In both cases ('Re:work' and 'Evoke'), they aspire to change the existing behaviour. In contrast to the low-grade teams, they seek to integrate the different levels of the product, by linking the abstract visions to concrete solution principles. As a result, the underlying intentions of the product is recognisable in the physical form, e.g. in the 'Re:work' project, the interaction in standing position at efficient meetings are easily decoded.

This final finding could indicate that prioritising of aspects is a key to help decision-making in the meaning construction process. Hence, this point implies to be a significant factor in order to succeed with communication of the intended product meaning.

\section{Conclusion}

In spite of that design is increasingly acknowledged as a process of meaning creation, there is very little guidance for how meanings are created in design teams on an operational level. In present literature, new product meaning is either addressed as a part of the design-driven approach to innovation (which mainly addresses the topic on a managerial level) or in the sense of the meaning communicated and reviewed through a product. Hence, literature rarely addresses the topic of meaning creation in terms of operational activities, that is in a design perspective. In this study, we aimed to increase understanding of meaning creation and related activities in novice design teams. In this process, we built upon visioning literature from design (Visioning in Design approach and the Vision-based model), and suggested to use 
these models as a starting point for understanding meaning creation as a design practice. The models were used to analyse and compare data from two facilitated workshops and follow-up interviews with master design student teams working on different projects for a furniture company.

The study indicates a significant difference between high-grade student teams and low-grade student teams in respect to their meaning creation process (summarised in Table 1). First of all, the high-grade students seemed to search for underlying reasons behind present user needs or behaviours and used this as a starting point for envisioning new kinds of future contexts with new meanings, whereas the lowgrade students identified present problems or challenges then subsequently searched for solution principles to these problems (or symptoms). Secondly, the high-grade students envisioned not only a new product context, but also new product experience, expression or interaction which added further levels or nuances to the new product meaning. Here, the low-grade students focused on identifying specific product features e.g. sound, light, etc. Finally, the high-grade students were able to clearly identify and prioritise the different aspects of the new product meaning, whereas the low-grade students were both challenged to communicate their aspired product meaning as well as clearly prioritise different aspects of this meaning.

Table 1. Comparison of high-grade and low-grade teams' meaning construction process

\begin{tabular}{|l|l|l|}
\hline $\begin{array}{l}\text { Approach to the identified } \\
\text { problem }\end{array}$ & $\begin{array}{l}\text { High-grade teams } \\
\text { beek the underlying user needs or } \\
\text { future context as a starting point } \\
\text { for meaning creation }\end{array}$ & $\begin{array}{l}\text { Seek to improve the existing } \\
\text { situation. Move to solution space } \\
\text { immediately after identifying the } \\
\text { problem }\end{array}$ \\
\hline Level of abstraction & $\begin{array}{l}\text { Add further levels or nuances to } \\
\text { the problem to the new product } \\
\text { meaning (abstract level) }\end{array}$ & $\begin{array}{l}\text { Identifying specific product } \\
\text { features (concrete level) }\end{array}$ \\
\hline $\begin{array}{l}\text { Prioritising and communication of } \\
\text { aspects }\end{array}$ & $\begin{array}{l}\text { Identify and prioritise the most } \\
\text { important aspect in the process. } \\
\text { The intention of the product is } \\
\text { easily decoded in the final } \\
\text { proposal (abstract and concrete } \\
\text { levels are linked) }\end{array}$ & $\begin{array}{l}\text { Prioritise more aspects as equally } \\
\text { important. The intentions of the } \\
\text { product are hardly decoded in the } \\
\text { final proposal (missing link } \\
\text { between abstract and concrete } \\
\text { level) }\end{array}$ \\
\hline
\end{tabular}

\section{Discussion}

In this study, we have taken part in the discussion on design's contribution to innovation which is still a neglected area in existing research. More specifically, we have explored what operational factors that influence successful meaning creation in design teams, and thus the main contribution of this study is to shed a new light to meaning creation from a design perspective. The limitation of the study is, however, that it is only based on data from four novice homogeneous design teams and therefore, it is not representative for general conclusions. On the other hand, it gives some indications of what might characterise a successful meaning construction process in novice design teams. Firstly, it indicates that successful meaning construction starts from an explorative approach where a deep understanding of the problem at hand is required. This understanding relates to the underlying user behaviour in the design situation and seems to be a crucial step in order to envision a future product meaning. Referring to the ViP model, it is not only the understanding of a past product, its interactions and context that is important for envisioning a future situation. More importantly, it is the understanding of past behaviour that is the significant step in meaning creation which becomes the starting point to create a new product meaning. Secondly, the study indicates that meaning is created from different aspects starting from the main vision or intention with the product. This vision or intention is based on the understanding of the past user behaviour and becomes the significant point to identify and prioritise relevant aspects to the new product meaning. In other words, it indicates that product meaning is built from a series of different aspects that is aspired to communicate the intended meaning through the tangible level of the product. These 
findings, however, is only based on the two successful cases but it outlines a potential working hypothesis to be tested in a similar future study.

Surprisingly, there was not identified any remarkable difference between the two workshops in what aspects each team prioritised as well as their understanding of the design situation. Not until the followup interview after hand-in of the final proposal, the new product meaning appeared clear - in spite of that some aspects of the final product were present from the beginning. This could imply that product meaning is a hard challenge to explicitly address in the early phases of the design process because it can only be understood as a whole, that is when the different aspects are bounded with the intention (abstract levels) and product characteristics (tangible level). Product meaning is thus a part of a complex system consisting of interdependent elements. In this perspective, the key skill of meaning construction may be the handling of these elements and the ability to construct them together in a meaningful way.

\subsection{Future research}

This study should only be seen in the light of being the first preliminary findings of a larger research project. More empirical research is needed in order to verify whether the identified successful factors of meaning construction holds true and how they potentially could be used to support novice design teams and non-designers when creating new product meaning. In this perspective, the study provides some indications to follow in future studies where the aim is to explore the characteristics of meaning creation in expert design teams in industry. This might be an important starting point to develop a design support that addresses the operational activities related to meaning creation in design teams. For that, we further argue that design literature on visioning might be an important first step in order to increase understanding on how design practice might contribute to innovation in terms of creation of new product meanings; meanings communicated through products and services, that provides truly meaningful experiences to people in the future.

\section{References}

Crilly, N. (2011), “Do Users Know What Designers Are Up To?”, International Journal of Design, Vol. 5 No. 3 , pp. $1-15$.

Dell'Era, C. and Verganti, R. (2009), "Design-driven laboratories: Organization and strategy of laboratories specialized in the development of radical design-driven innovations", $R \& D$ Management, Vol. 39 No. 1, pp. 1-20. https://doi.org/10.1111/j.1467-9310.2008.00541.x

Dell'Era, C. and Verganti, R. (2010), “Collaborative Strategies in Design-intensive Industries: Knowledge Diversity and Innovation", Long Range Planning, Vol. 43 No. 1, pp. 123-141. https://doi.org/10.1016/j.lrp.2009.10.006

Desmet, P.M.A. and Hekkert, P. (2007), "Framework of Product Experience", International Journal of Design, Vol. 1 No. 1, pp. 57-66.

Goto, S. and Ishida, S. (2014), "The Contribution of Technology to Improving Meanings: The Quantitative Analysis of Meanings", Proceedings of IEEM 2014, the International Conference on Industrial Engineering and Engineering Management, Bandar Sunway, Malasya, December 9-12, 2014, IEEE, pp. 1038-1041. https://doi.org/10.1109/IEEM.2014.7058796

Harrison, S., Tatar, D. and Sengers, P. (2007), "The three paradigms of HCI", Proceedings of CHI'07 / CHI Conference on Human Factors in Computing Systems, San Jose, California, USA, April 30 - May 3, 2007, ACM, New York, USA, pp. 1-18.

Hekkert, P. and van Dijk, M. (2011), Vision in Design - A Guidebookfor Innovators, BIS Publishers, Amsterdam.

Hill, R.C. and Levenhagen, M. (1995), "Metaphors and Mental Models: Sensemaking and Sensegiving in Innovative and Entrepreneurial Activities", Journal of Management, Vol. 21 No. 6, pp. 1057-1074. https://doi.org/10.1177/014920639502100603

Jahnke, M. (2013), Meaning in the Making-Introducing a Hermeneutic Perspective on the Contribution of Design Practice to Innovation, $\mathrm{PhD}$ thesis, University of Gothenburg.

Kazmierczak, E.T. (2003), "Design as Meaning Making : From Making Things to the Design of Thinking", Design Issues, Vol. 19 No. 2, pp. 45-59. https://doi.org/10.1162/074793603765201406

Krippendorff, K. (2006), The Semantic Turn: A New Foundation for Design, CRC Press, Taylor \& Francis, Boca Raton, Florida.

Lerdahl, E. (2001), Staging for creative collaboration in design teams - Models, tools and methods, Norwegian University of Science and Technology. 
Magnusson, J. and Nilsson, J. (2011), Designing Innovation of Meanings - A Competitive Advantage, Master thesis, Jönköping International Business School, Jönköping University.

Öberg, Å. (2015), Striving for Meaning - a Study in Innovation Process, PhD thesis, Mälardalen University Sweden.

Rampino, L. (2011), "The innovation pyramid: A categorization of the innovation phenomenon in the productdesign field”, International Journal of Design, Vol. 5 No. 1, pp. 3-16.

Rindova, V.P. and Petkova, A.P. (2007), "When Is a New Thing a Good Thing? Technological Change, Product Form Design, and Perceptions of Value for Product Innovations”, Organization Science, Vol. 18 No. 2, pp. 217-232. https://doi.org/10.1287/orsc.1060.0233

Sarpong, D. and MacLean, M. (2012), "Mobilising differential visions for new product innovation”, Technovation, Vol. 32 No. 12, pp. 694-702. https://doi.org/10.1016/j.technovation.2012.07.003

Verganti, R. (2003), "Design as brokering of languages: Innovation strategies in Italian firms", Design Management Journal, Vol. 14 No. 3, pp. 34-42. https://doi.org/10.1111/j.1948-7169.2003.tb00050.x

Verganti, R. (2009), Design-Driven Innovation: Changing the Rules of Competition by Radically Innovating What Things Mean, Harvard Business Review Press, Boston, Massachusetts.

Verganti, R. and Öberg, Å. (2013), "Interpreting and envisioning - A hermeneutic framework to look at radical innovation of meanings", Industrial Marketing Management, Vol. 42 No. 1, pp. 86-95. https://doi.org/10.1016/j.indmarman.2012.11.012

Ylirisku, S., Halttunen, V., Nuojua, J. and Juustila, A. (2009), "Framing Design in the Third Paradigm", Proceedings of CHI'09 / the 27th Conference on Human Factors in Computing Systems, Boston, USA, April 4-9, 2009, ACM, New York, USA, pp. 1131-1140. https://doi.org/10.1145/1518701.1518874

Line Sand Knudsen, PhD Fellow

Aalborg University, Department of Architecture, Design and Media Technology

Rendsburggade 14, 9000 Aalborg, Denmark

Email: 1sk@create.aau.dk 